\title{
Introducing Information Literacy to Mathematics Classrooms: A Cross-Case Analysis
}

Ander W. Erickson

University of Washington Tacoma, awerick@uw.edu

\section{Recommended Citation}

Erickson, Ander W.. "Introducing Information Literacy to Mathematics Classrooms: A Cross-Case Analysis." Numeracy 12, Iss. 1 (2019): Article 7. DOI: https://doi.org/10.5038/1936-4660.12.1.7 


\title{
Introducing Information Literacy to Mathematics Classrooms: A Cross-Case Analysis
}

\author{
Abstract \\ This study employs a cross-case analysis to explore the demands and opportunities that arise when \\ information problem-solving tasks are introduced into college mathematics classes. Mathematics \\ teachers at three universities developed and introduced tasks that required students to seek out, evaluate, \\ and synthesize quantitative claims from disparate information sources. The results focus on a \\ comparison of how the teachers balanced content-specific instructional demands with the information \\ literacy goals of the tasks that they created. Three tensions were identified through this analysis: the need \\ to balance mathematical content with opportunities for students to engage in a realistic approximation of \\ the information problem-solving process, the limitations imposed by the students' mathematical \\ knowledge, and the ill-defined nature of teachers' desired outcomes with respect to student dispositions \\ towards quantitative claims. These findings provide tools for better understanding how to productively \\ incorporate information literacy practices into subject-specific instruction while maintaining a focus on \\ content goals.
}

\section{Keywords}

instructional activities and practices, post-secondary education, information literacy, information-based problems

\section{Creative Commons License}

(c) (i) (8)

This work is licensed under a Creative Commons Attribution-Noncommercial 4.0 License

\section{Cover Page Footnote}

Ander Erickson, PhD, is an Assistant Professor of Mathematics Education at University of Washington Tacoma. He is interested in developing students' abilities to use online resources to critically evaluate quantitative claims and in the exploration of how students are currently using online resources to study mathematics. 


\section{Introduction}

Contemporary mathematics students enjoy immediate access to varied sources of information outside the classroom. They can look up vocabulary terms on Wikipedia, find context for a statistics problem by accessing governmental data sets directly, and track down discussions of test problems on various Q\&A websites. While mathematics instruction has historically been focused on sequestered problem-solving (Bransford \& Schwartz 1999), or the ability to solve problems without any outside aid, students will more realistically encounter quantitative claims embedded in an information environment filled with social and technological tools they can use to help them evaluate and synthesize claims. The type of problem-solving most efficacious for these types of situations can be practiced through the use of information-based problems (Walraven et al. 2008) or those problems that require "students to identify information needs, locate corresponding information sources, extract and organize relevant information from each source, and synthesize information from a variety of sources" (Walraven et al. 2008, 623). Erickson (2016) argues that the use of informationbased problems is not just preferable, but that it is also necessary if mathematics instruction is to help prepare students for the quantitative arguments that they may expect to encounter in their everyday lives (Paulos 1988; NCED 2001). However, there have been very few studies of what transpires in STEM classrooms when teachers introduce such problems and there have been no studies that take place in the context of a mathematics classroom.

This paper presents a cross-case analysis (Stake 2013) of three different undergraduate mathematics teachers who worked with their students on statisticsfocused tasks that require the students to seek out, evaluate, and make use of information that they find online. The use of information-based problems has been studied in the context of science education (Hoffman et al. 2003; Wiley et al. 2009) and history education (Britt \& Aglinskas 2002). However, those studies reported on experiments that took place apart from classroom instruction, and therefore those who crafted the activities did not need to concern themselves with the obligations entailed in classroom instruction (Herbst \& Chazan 2012), such as the need to respect institutional time constraints and address the content required by the discipline. Accordingly, the present study is unique for two reasons: a) it focuses on the discipline of mathematics, and (b) the tasks were incorporated into ongoing courses. The analysis of the design and implementation of these information problem-solving mathematics tasks provides a window into the balance teachers must strike between the teaching of mathematical content and the teaching of information literacy practices. In particular, the analysis addresses the following research questions: 
- What are possible roles for mathematical content in an information-based problem that has been introduced into a quantitative literacy-focused mathematics class?

- What tensions do mathematics teachers have to navigate when balancing information problem-solving and quantitative literacy learning goals?

\section{Theoretical Framework}

\section{Quantitative Literacy and Statistical Literacy}

A basic facility with numbers, the ability to interpret and employ mathematical formulas, a sense of confidence and efficacy when confronted with mathematical arguments: these are all broadly used, if partial, definitions of quantitative literacy (Steen 2001; Cullinane \& Treisman 2010; Wilkins 2010; Watson 2013). In practice, the type of mathematics most often associated with the quantitative literacy construct (Steen 2004) could be characterized as financial mathematics (e.g., the formulas necessary to calculate interest or equal payments over time) or other data-driven mathematical approaches (e.g., estimators produced by scientific polls, measures of correlation and statistical significance that accompany the reporting of scientific findings, basic probability theory employed to understand relative risk in the context of health care or gambling). While the present project is not intended to define which mathematical content best supports quantitative literacy, it is the case that the three instructors with whom I collaborated decided to focus on statistics-related content. As such, it will be worthwhile to look more closely at how statistical literacy has been defined.

Iddo Gal proposed most widely adopted statistical literacy model (2002). In presenting this model, he characterizes students as interacting with data in two distinct ways. First, in reading contexts students operate as data consumers who are confronted with the statistical analysis of data in the form of text, tables, and diagrams. These interactions leverage the individual's existing quantitative literacy whether they are passively consuming the information or intend to make use of the information for their own purposes. Alternatively, students may find themselves in enquiry contexts where they take on the role of data producer or data analyzer. In these cases, they will actually work to collect, analyze, and/or disseminate statistical information. Gal (2002) argues that the literacy skills required for the successful navigation of reading contexts versus enquiry contexts are related but also very distinct. It should be further emphasized that the development of quantitative or statistical literacy has little to do with the development of mathematicians given that the bulk of students will most likely be working as scientists or technicians in a variety of fields, with the field of mathematics as only one among many possible outcomes. 
Reading contexts refers to those situations where we encounter quantitative claims made by others. The quantitative literacy required for reading contexts differs from enquiry contexts because the merits of such claims cannot be based solely on an individual's analysis of the argument at hand. Rather, they are vetted through peer review and confirmed (or contested) through follow-up studies, which are also reviewed by those who work in the same field (Norris 1995; Popper 2014). This perspective imposes limits on the efficacy of quantitative literacy in evaluating quantitative claims but does not completely eliminate its importance. For example, quantitative literacy may be more necessary in order to understand the import of a quantitative claim in the first place. Further, following arguments made by Norris (1995) and Keil (2010) about science literacy, if we broadly conceptualize quantitative literacy to include knowledge of the structures through which quantitative claims are generated, validated, and disseminated, then one can say that a student with such understanding will be better equipped decide when quantitative claims ought to be granted authority and to what extent they require further corroboration and sourcing. The natural pedagogical question is whether there are tasks that will help students practice such skills.

\section{Information-Based Problems in the Mathematics Classroom}

While curriculum developers have developed activities that superficially appear to position students as data consumers, the framing of such tasks may fail to prepare students for the actual work associated with successful navigation of reading contexts. In order to support this claim, we will look at a task intended to help develop students' quantitative literacy. In Diefenderfer's (2009) Case Studies for Quantitative Reasoning, students are given an editorial in which the author argues that federal guidelines on fuel efficiency will end up costing the country more money than it will save. They are then asked to read the editorial and are provided with several guiding questions that encourage them to analyze a quantitative claim contained in the article. This activity provides students with an opportunity to create a linear equation to model fuel savings over time, practice calculating compound interest, and to consider which mathematical model is most appropriate for confirming the claims made in the article. All of this work, however, is directed toward evaluating the author's claims based on the premises set forth in the article without consideration of the manner in which such claims are actually validated as part of the scientific process. Specifically, most people reading such a claim are not in a position to know what they do not know about the topic in question.

We first note (see Fig. 1) that the truth of any quantitative claim is not determined by the author who happens to be presenting the claim. Rather, its validity is established by the relevant epistemic community (Haas 1992) which 
can be defined as those who possess the expertise to rule on the truth of the claim. In other words, students would need to seek out and make use of the knowledge of others (Norris 1995; Erickson 2016; Kahan et al. 2017) by finding experts on whom they have good reason to rely. The problem as originally stated does not afford students an opportunity to engage in this practice. They are not asked to seek out and evaluate those sources of information that might either corroborate or challenge the argument found in the editorial. An information-based problem (Walraven et al. 2008), however, requires that the student seek out and evaluate sources outside the classroom. They must "identify information needs, locate corresponding information sources, extract and organize relevant information from each source, and synthesize information" (Walraven et al. 2008, 623)in a process called information-problem solving. That is why the present study focuses on how mathematics teachers and their students handle the introduction of information-based problems to their classrooms, and on whether and how these problems afford opportunities for the use of content knowledge.

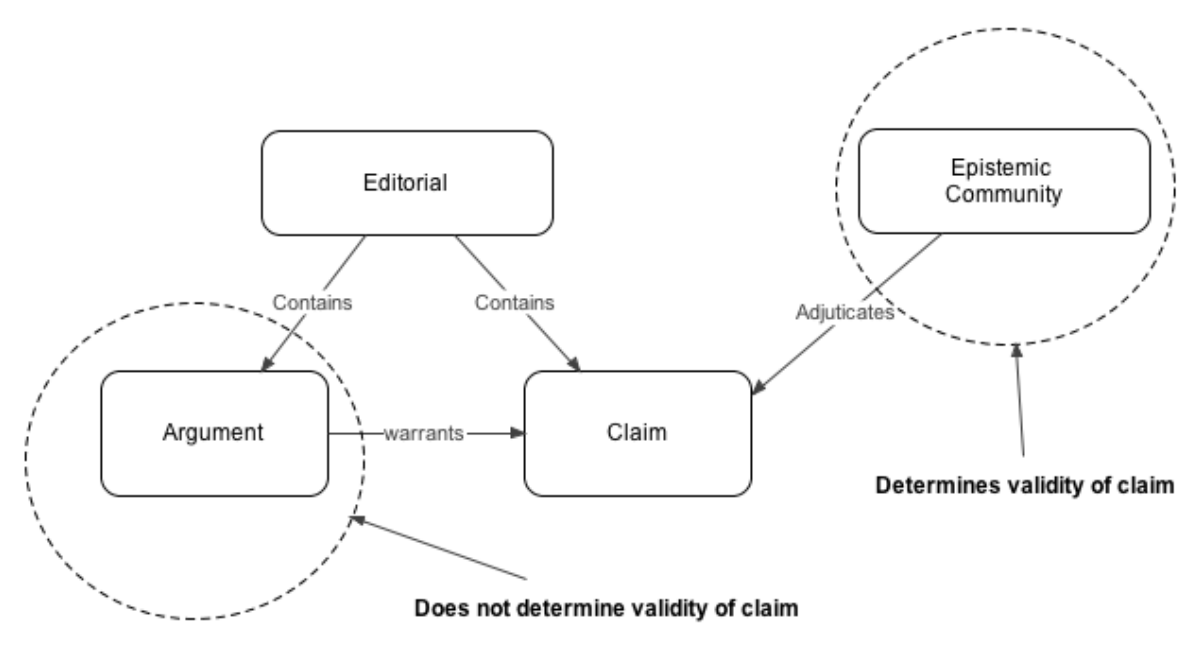

Figure 1. Relationship between Editorial, Claim, and Epistemic Community

\section{Information-Based Problems and Content Knowledge}

Information-based problems require students to seek information that they do not already possess. In their introduction to a special issue of the journal Learning and Instruction devoted to this topic, Brand-Gruwel and Stadtler (2011) explain that "due to the growing specialization in all scientific areas there is a large number of (everyday) problems for which knowledge is necessary that exceeds 
what an individual might know as part of his or her general education," so an "individual needs to access external sources of knowledge for solving these problems" (Brand-Gruwel \& Stadtler 2011, 176). The importance of generic search and evaluation skills as part of the information problem-solving process is demonstrated by the effectiveness of the SEEK web tutor (Graesser et al. 2007; Wiley et al. 2009), a tool that supports students in solving information-based problems by encouraging the evaluation of the quality of search results and the authorship and support for claims found within specific sources. These experiments provide evidence of learning gains on some measures (Graesser et al. 2007) and greater differentiation in judgments of reliability (Wiley et al. 2009). While the findings suggest that information-seeking skills are an important part of the information problem-solving process, they also suggest that we need a better understanding of the role of content knowledge in the solving of such problems.

There is work in this area suggesting that support for generic searching and evaluation skills will be most productive when applied to an area where students have relevant domain knowledge and, vice-versa, that the application of domain knowledge to an information-based problem ought to be supported by generic instruction in the search for and evaluation of sources. Bråten et al. (2011) find that students with low content knowledge (in this case, related to climate change) are more likely to misplace their trust and less able to judge the relevance of sources. Furthermore, Kienhues et al. (2011) find that inquiry into an informationbased problem is associated with the development of more advanced epistemic beliefs when students are exposed to contradictory sources of information. Other strands of research also support the move to introduce information problem solving to discipline-specific courses. Work on disciplinary literacy calls for instructors to help students think more carefully about how professionals in STEM fields locate and evaluate mathematical resources (Moje 2007; Schleppegrell 2007; Shanahan \& Shanahan 2012) as part of their problem-solving process, and researchers in the information sciences also argue for the importance of locating information literacy instruction within the disciplines (Grafstein 2002; Rader 2002; Tuominen et al. 2005). This study supports that call for action by exploring the challenges that arise when information-based problems are introduced in a mathematics course.

\section{Methodology Context}

This cross-case analysis is the product of a collaboration with teachers of terminal mathematics courses for non-STEM majors. These courses were chosen as a venue because terminal mathematics courses have more flexibility with respect to curriculum than traditional content courses and because they take the 
development of their students' quantitative literacy skills as a learning objective. The first location ("Phi University") is a public Research I university and the course was a summer bridge class for rising freshmen from underrepresented areas of the state. The students had been directed to this course because they did not intend to pursue a STEM major, hence there was a presumption that students participating in the course would have less confidence in their mathematical abilities than the average student, and the instructor wanted to help them gain confidence in their mathematical abilities. The second location ("Rho University") is a regional public university with popular nursing and education programs. The students enrolled in this course were belatedly fulfilling a quantitative reasoning requirement that they needed to meet in order to graduate. As reported by the instructor, most of the students in this course did not enjoy mathematics and had, therefore, postponed taking the required course as much as they were able. A plurality of students in this particular class was nursing students who tended to work with one another when given the opportunity. The third location ("Delta University") is a public doctoral research university with popular nursing and education programs. Students from both of these programs were well represented in the class. The student composition of this course was very similar, in nature, to the course at Rho University, largely serving students who needed to fulfill the institution's quantitative reasoning requirement before they could graduate. An overview of the three locations is provided in Table 1.

Table 1

Characteristics of the Research Sites

\begin{tabular}{|c|c|c|c|c|c|}
\hline $\begin{array}{c}\text { University Name / } \\
\text { Instructor* }\end{array}$ & $\begin{array}{l}\text { Course } \\
\text { Name* }\end{array}$ & Students & Topics & Structure & $\begin{array}{c}\text { Mathematics } \\
\text { Content }\end{array}$ \\
\hline $\begin{array}{l}\text { Phi University } \\
\text { (research)/ } \\
\text { Tim }\end{array}$ & $\begin{array}{c}\text { Topics in } \\
\text { Mathematics }\end{array}$ & $\begin{array}{c}22 \text { entering } \\
\text { freshman, liberal } \\
\text { arts majors }\end{array}$ & $\begin{array}{c}\text { gun control, marijuana } \\
\text { legalization, single-sex } \\
\text { education, death } \\
\text { penalty }\end{array}$ & $\begin{array}{l}\text { debate } \\
\text { format }\end{array}$ & $\begin{array}{c}\text { representing data } \\
\text { with charts and } \\
\text { figures }\end{array}$ \\
\hline $\begin{array}{l}\text { Rho University } \\
\text { (regional)/ } \\
\text { Anne }\end{array}$ & $\begin{array}{l}\text { Quantitative } \\
\text { Reasoning }\end{array}$ & $\begin{array}{l}14 \text { juniors and } \\
\text { seniors, many } \\
\text { prospective } \\
\text { nursing students }\end{array}$ & $\begin{array}{c}\text { autism and } \\
\text { vaccination, the } \\
\text { Mozart effect, gun } \\
\text { control, health care } \\
\text { reform }\end{array}$ & $\begin{array}{l}\text { small-group } \\
\text { discussions }\end{array}$ & $\begin{array}{l}\text { correlation } \\
\text { coefficients }\end{array}$ \\
\hline $\begin{array}{l}\text { Delta University } \\
\text { (doctoral)/Ivan }\end{array}$ & $\begin{array}{l}\text { Mathematics } \\
\text { in Today's } \\
\text { World }\end{array}$ & $\begin{array}{l}24 \text { juniors and } \\
\text { seniors, many } \\
\text { prospective } \\
\text { nursing and } \\
\text { education } \\
\text { students }\end{array}$ & $\begin{array}{c}\text { autism and } \\
\text { vaccination, gun } \\
\text { control, murder rate, } \\
\text { vehicular accidents, } \\
\text { employee prospects }\end{array}$ & $\begin{array}{l}\text { small-group } \\
\text { presentation }\end{array}$ & $\begin{array}{l}\text { sampling } \\
\text { methodologies }\end{array}$ \\
\hline
\end{tabular}

*These are pseudonyms.

The three universities varied in terms of their racial/ethnic demographic breakdown, with black or African American students underrepresented at two of 
the universities (Phi and Rho), and Hispanic/Latino students are underrepresented at all three locations. It was not possible to collect classroom-level demographic data, but the school-level data is presented in Table 2 .

Table 2

Racial/Ethnic Demographics at the Research Sites

\begin{tabular}{|c|c|c|c|}
\hline Group & Phi University & Rho University & Delta University \\
\hline $\begin{array}{l}\text { American Indian or } \\
\text { Alaskan Native }\end{array}$ & $0.2 \%$ & $0.3 \%$ & $0.3 \%$ \\
\hline Asian & $12.7 \%$ & $2.6 \%$ & $4.4 \%$ \\
\hline $\begin{array}{c}\text { Black or } \\
\text { African American }\end{array}$ & $4.3 \%$ & $19.3 \%$ & $7.5 \%$ \\
\hline Hispanic/Latino & $4.6 \%$ & $4.7 \%$ & $3.1 \%$ \\
\hline $\begin{array}{l}\text { Native Hawaiian or } \\
\text { Pacific Islander }\end{array}$ & $0.0 \%$ & $0.1 \%$ & $0.1 \%$ \\
\hline White & $61.4 \%$ & $65.1 \%$ & $75.1 \%$ \\
\hline Unknown & $9.9 \%$ & $5.8 \%$ & $7.5 \%$ \\
\hline Non-Resident Alien & $6.9 \%$ & $2.1 \%$ & $2.0 \%$ \\
\hline
\end{tabular}

The instructors at each of these locations were initially contacted by the author via an e-mail that briefly introduced the idea of information-based problems. After follow-up phone conversations, all three instructors welcomed the opportunity to introduce such problems into their classrooms. We met periodically as the instructors were planning their courses and, with the instructors taking the lead, established what the information-based problems would look like at each location. At Phi University, the students took part in a series of classroom debates. Each pair of students were randomly assigned to either the pro or con side of a controversial topic, and were required to conduct research in order to find support for their argument with the condition that they must include some statistical evidence. At Rho University, we developed a two-part activity where students were asked to look for articles containing a causal claim about one of two issues: the connection between vaccines and autism or the Mozart effect. ${ }^{1}$ They had to determine whether the sources they located included a correlation coefficient and share what they found with their peers in small groups. After those

\footnotetext{
${ }^{1}$ The conjecture that an individual will perform better on mathematics tests if they listen to classical music while studying (Hetland 2000).
} 
groups of students tried to come to a consensus about whether the causal claim was warranted, they then took part in a whole-group discussion. ${ }^{2}$ The students at Delta University produced small-group presentations in which they assessed the sampling methodology described in a research article that made use of inferential statistics or a scientific poll. ${ }^{3}$

\section{The Multi-Case Analysis}

In order to investigate the role of mathematics in these information-based problems, I conducted a multi-case analysis (Stake 2013) of the three sites. The quintain, or the phenomenon of interest for this cross-case analysis, is the introduction of information-based problems to an undergraduate mathematics course. The data for this study includes pre- and post-activity interviews with the instructors at each of the three sites, supplementary interviews with teaching assistants and students, field notes taken while observing instruction prior to the introduction of the information-based problems, video and audio recordings of the in-class component of the activities, and copies of the work that the students submitted. Following Stake (2013), I developed themes based on my research questions that I then used as an analytical lens for the development of case reports for each of the three sites. ${ }^{4}$ After writing up the case reports, I cross-referenced case-specific observations (see Fig. 2 for examples relevant to the present analysis) with the themes of the larger study. This allowed me to warrant themebased assertions which, in turn, informed the final cross-case assertions about the introduction of information-based problems to undergraduate mathematics classrooms. The cross-case assertions related to the students' opportunities to interact with mathematical content as part of their information problem-solving process is presented below.

Case-Specific Observation A: In the first session, students were searching for articles and then looking for a correlation coefficient within the articles, but they rarely found a correlation coefficient.

Case-Specific Observation B: Students preferred to work with information resources that contained mathematics that they could understand.

Case Specific Observation C: In the first session, the teacher prioritized the identification of a particular piece of mathematical content, the correlation coefficient, to the exclusion of any discussion of the credibility of sources.

Figure 2. Examples of case-specific observations from Rho University

${ }^{2}$ A second activity had the students look for confidence intervals, but I will focus on the first activity for this analysis. A complete description of both activities appears in Erickson (2015).

${ }^{3}$ A second activity at Delta University had students gather demographic data to calculate conditional probabilities of interest (e.g., post-graduation employment, gun violence statistics). A complete description of both activities appears in Erickson (2015).

${ }^{4}$ See Erickson (2015) for a complete cross-case analysis including individual case reports. 
The teachers with whom I collaborated were taking on a unique challenge when they decided to introduce information-based problems to their mathematics classroom. While they agreed that their students would benefit from an opportunity to engage in information problem solving, they had to continue to teach their students mathematics through these problems. While I explained the information literacy framework and provided the teachers with resources to support their students' information-seeking, I intentionally let the teachers decide how they wanted to introduce the concepts at stake and the teachers at each of the three locations approached the challenge in distinct ways. In order to describe the role that mathematical work played in these problems, I employ the academic task construct as originated by Doyle and Carter (1984) and developed in the mathematics education context by Herbst (2006). Tasks are "situational structures that organize and direct thought and action" (Doyle \& Carter 1984, 130) in which the structuring of classroom work is described as a set of operations employed on a set of resources in order to achieve a previously specified product. Herbst (2006) further draws on Brousseau (1997) to distinguish the mathematical problem on which the task is centered from the way in which students engage with the problem. As such, I will use the term task to refer to the entire activity structure that centers on the information-based problems created by the three instructors.

As we shall see, the task perspective helps distinguish the role and nature of the mathematical content in the implementation of the information-based problems. This finding addresses the first research question ("What are possible roles for mathematical content in an information-based problem that has been introduced into a quantitative literacy-focused mathematics class?") by providing a set of examples of how mathematical content can be incorporated in information-based problems. Furthermore, the academic task framework operates with the cross-case analysis to address the second research question ("What tensions do teachers have to navigate when balancing information problemsolving goals and quantitative literacy goals?") by providing the means to highlight the points at which the two types of desired outcomes come into conflict with one another. Those results are derived from an analysis of the respective tasks as well as my observations of the students' actual work in each classroom.

\section{Results}

By allowing teachers to develop information-based problems best suited to their classrooms and instructional goals, I was able to study and contrast three very different types of information-based activities. The variation across sites helped inform my development of a theory about the range of ways that mathematical 
content knowledge aligns with information literacy practices in such settings. I will begin with a general description of each of the three cases before describing the role that mathematics plays in the operations, resources, and products that together formed the tasks in which the students were engaged. These results allowed me to develop three cross-case observations about the tensions that arise when mathematical content and information literacy work in tandem. I present the three tensions at the end of this section.

\section{Phi University: An Independent Mathematical Task}

The mathematical component of the debates at Phi University almost functioned as a freestanding task of its own. Tim decided that his students would provide a statistical chart or diagram (e.g., bar graphs, histograms, pie charts) as part of their argument:

I made the decision at some point that I didn't want them to just download graphics off the Internet because I was worried that if they did that, they would download a bunch of fancy graphics that they didn't really quite comprehend and then it would be too much information for anybody in the audience to comprehend too. And so I figured the way around that is that I would have them do it, they read the section on how to present data, that's section two of that chapter, how to present data, ideas on how to present data, and so let's make them do it. I think that was a good decision. (Tim, Session 131408, Lines 73-79)

I refer to the creation of these graphics as an almost freestanding task because the creation of the graphics could have been an entirely distinct task from the debate except that the students still had to seek out the sources containing the statistics that would inform their visuals. Thus, the overlap between information literacy and quantitative literacy for this activity was centered on the need to find resources that could be used to create a graphic. We will see that this resulted in some tension for the students and instructor that might not exist if the resources had been provided for the students, as would be the norm for such an activity in a mathematics classroom. Using the language of academic tasks, the operations that were part of the debate task (e.g., using a search engine, scanning search results) provided the resources that would be used to realize the mathematical task (i.e., the creation of the graphics).

While the students had to present these visuals as part of the debate activity, the mathematical task could exist independently of its role in the debate as long as equivalent resources were made available. Conversely, a debate could have taken place without students having to create and make use of such charts or graphs. Nonetheless, by introducing this mathematical task, Tim was able to simultaneously avoid the introduction of graphics that would be too difficult for his students to interpret and to create a relatively well-defined mathematical task within the larger information problem-solving task, which he would subsequently be in a better position to appraise as mathematical work. 


\section{Rho University: Mathematical Content as a Marker of Credibility}

At Rho University, Anne had her students seek out multiple information sources that addressed a driving question. Most students investigated whether there is evidence of a causal connection between vaccinations and autism, while the remaining students investigated the Mozart effect, or the claim that listening to classical music the night before a mathematics test will result in improved performance (Hetland 2000). She also created a mathematical task that was part of a larger information problem-solving task, but in this case the mathematical work was tied to the students' credibility assessment. Specifically, Anne described the presence of a correlation coefficient as a marker of whether a student should trust any claims made about a correlation between two variables. As was the case at Phi University, the students at Rho were to submit a product that included the mathematical work (i.e., the identification and interpretation of a correlation coefficient) alongside information problem-solving work that did not necessarily draw on the mathematical content that students were learning. That said, this activity was not an independent mathematical task because the presence (or lack) of this mathematical content was being presented as an important part of how students were to assess source credibility. Hence, the student's mathematical content knowledge became part of the process of seeking out and evaluating information sources.

\section{Delta University: Evaluating a Source's Statistical Claims}

The activity at Delta University as developed by Ivan was structurally similar to the mathematical sub-task at Phi University in that the students had to first find a source they would then use as the object of their mathematical work. The product at Delta University was the students' analysis of the sampling strategy used by the scientific poll or research article that they found. Thus, they were being asked to do more than simply seek out and recognize mathematical/statistical content; rather they were being asked to evaluate one part of the statistical analysis used by their source. The result of their evaluation could then be used to determine how much credibility to grant the source. In a sense, Ivan was going one step further than Anne in order to tie his students' quantitative literacy skills to the information problem-solving process. Whereas Anne stated that the seeking out and identification of a correlation coefficient is a necessary part of the credibility assessment of relevant quantitative claims, Ivan suggested that the credibility of statistical claims requires the reader to analyze at least some parts of the experimental design used to establish the claims in the first place. 


\section{Taxonomies of the Mathematical Tasks}

In each of the three cases, the students had to locate outside sources of information, but their requirements differed in several crucial ways, each of which can be linked to one of the three elements of an academic task: resources, operations, and the product (Doyle \& Carter 1984).

Resources. A defining feature of information-based problems is that students are given the opportunity to seek out sources of information on their own. In such a context, resources include both the information sources (e.g., newspaper and journal articles, blogs, government statistics) and the mechanisms through which those information sources are sought out. For example, in all three cases, students primarily made use of the Google search engine to find information sources, although there were exceptions, such as a group of nursing students at Rho University who made use of articles from their major courses as part of their exploration of the vaccines/autism debate. I will address how the teachers' framing of the information-based problems influenced the resources available to the students, leaving the students' credibility assessment of those resources for the next section.

The instructions for these information-based problems limited the students' gathering of information sources in ways that might not be immediately obvious. At Phi University, students were looking for information that supported their side of a debate, so they generally sought out editorials and blog posts that argued for a particular perspective. They would look through different information sources that supported their position until they found at least one that used data as part of its argument so that they could use that data to create the chart or graph that was required by the assignment. This course of action suggests that they were not focused on assessing the credibility of the sources they encountered. This potential disregard for credibility was further corroborated by the fact that the only reason the students provided for disregarding a source was when they could not understand the mathematical content enough to make use of it as a tool for convincing their peers.

At Rho University, the students collected more information sources than those at Phi University and were not required to engage with mathematical content to the same degree because Anne had only asked her students to identify whether or not a correlation coefficient was present. Unfortunately, most of the students found information sources that did not contain correlation coefficients, thus driving the conclusion that there were simply not very many credible information sources.

Delta University differed most dramatically from the other two cases in terms of the amount of information sources collected. Students were asked to evaluate the sampling methodology used by a poll, so they only needed to find a single 
information source. As at Phi University, there were many cases where students moved on from an information source because they did not feel comfortable evaluating mathematical claims that were too complicated for them to understand, but they all looked at two or three articles at most.

Operations. Looking across these academic tasks, the students engaged in a number of operations specific to information seeking: they sought out information via the Internet, engaged in credibility assessment, justified their choices, and presented the results to their peers. Indeed, the information-seeking operations available to the students were unconstrained by any of the instructors. The students were free to locate information sources however they saw fit. In practice, as reflected in the description of resources above, this meant that they were primarily choosing terms to enter into the search engine and choosing information sources based on the summaries found in the search results. This pattern of activity is consistent with current research on the information-seeking behavior of college students (Head 2013). While I am primarily concerned here with outlining the tasks and the opportunities that they provided for the students to learn, there were some important differences in behavior between cases based on the students' goals. Namely, at Delta University the students would tend to seek out one or two information sources and then proceed to analyze the source as per the task requirements whereas the students at Phi and Rho University sought out a number of sources in order to support their side of the argument, in the former case, or to learn more about the topic in question, in the latter case.

The use of mathematics, on the other hand, was quite a bit more varied across the locations. At Phi University, students were primarily collecting information that would be used to buttress the argument they planned to make as part of the debate, so they needed to create some type of chart or graph that could be presented to their peers. This activity did not generally involve much, if any, computation because they were not analyzing raw data; rather they were generally taking data that was already presented in tabular form and turning it into an appropriate graph. At Rho University, the students had been asked to choose the sources that they deemed most credible, to explain why they found the sources credible, and to discuss those sources with a small group of their peers. Accordingly, they engaged in less mathematical work than the students at Phi University. In fact, the correlation coefficient that they were seeking out was most often missing from the information sources that they located. At Delta University, the students had to engage in much more complex quantitative analysis relative to the other two cases. They had to provide a critique of the sampling methodology of their information source which included assessing the appropriateness of the sample size and whether the approach would produce a representative sample. 
Product. The students at Phi University presented their peers with a fully formed argument for their assigned side of a controversial issue. This had to include some mathematical content: a statistical chart or graph (e.g., pie charts, bar graphs, histograms). These charts and graphs were only one part of what they presented as they participated in the debate. They were allowed and even encouraged to make entirely non-mathematical arguments as well, but all of the students had to include at least one visual representation of statistics as part of their argument. They also had to interpret the chart or graph for their audience, so the audience was treated to a demonstration of how to interpret a statistical graph as part of each presentation. Notably, this type of interpretive activity is an important component of Gal's (2002) statistical literacy model.

At Rho University, the product was a written account of whether and why the students found their chosen information sources to be credible. They also engaged in a discussion with a small group of their peers in which the entire group was asked to come to a consensus about which information sources were the most credible or to explain why they were unable to agree. While the students could choose use any criterion for credibility, they needed to address whether a given source contained a correlation coefficient as part of their assessment. The teacher had already established that the presence of such a mathematical object was an important marker of credibility (she framed this as a need for researchers to "show their work"), so the presence, or absence thereof, figured prominently in the students' writings and in their conversations with one another. Unfortunately, the correlation coefficients were missing from the students' articles more often than not, so their peers were not actually being exposed to mathematical content as part of the product of the activity.

At Delta University, the product of the activity was much more heavily focused on presenting a mathematical argument than at either of the other two locations. The students presented a description and critique of a sampling strategy, so the presentation always contained some evidence of mathematical work. This requirement also meant that the teacher had an opportunity to encounter student misconceptions and mistakes. We shall see more about this result as I present three tensions between the quantitative literacy and information literacy aspects of the cases.

\section{First Tension: A "Successful” Activity vs. Deeper Mathematical Work}

As outlined above, the students at Delta University engaged in much more mathematical work than the students at Phi and Rho University. Ironically, those latter activities were felt to be very successful by Tim and Anne, while Ivan expressed some frustration with the results of his activity. Upon further questioning, Ivan's dissatisfaction was largely a side effect of a positive 
development; the presentations had afforded Ivan the opportunity to observe gaps in his students' knowledge of basic statistical concepts, an opportunity that did not exist at either of the other two locations, at least not to the same extent. In a subsequent interview with Ivan, he expressed satisfaction that he was able to discover that those students did not fully understand some of the more basic statistical concepts that he had been trying to teach them and said that he would incorporate a similar activity into future iterations of the course in order to discover whether students could apply what they were learning to real-world scenarios.

The fact that neither Tim nor Anne experienced such frustration does not mean that their students had greater content mastery. While the activities they created required the students to represent and/or recognize mathematical content, the students did not have to engage in the sort of problem solving required for Ivan's class. Hence, there were fewer opportunities for students to demonstrate whether they actually understood the mathematical content at stake. Recognizing the presence of a correlation coefficient is different than interpreting or using it.

There is a fundamental tension here that is inherent in any mathematical activity that involves the practice of information literacy. The information literacy process calls for students to seek out multiple information sources and to efficiently categorize them according to their credibility along with the extent to which they corroborate one another. The more a student engages with that process, the less time a student has to carefully analyze the mathematics underlying any specific quantitative claims contained therein.

\section{Second Tension: Mathematical Knowledge as Invitation and Barrier}

The relationship between the students' mathematical knowledge and the assessment of their sources' credibility operated in two somewhat contradictory directions. Notably, both of these relationships were observed in all three cases. First, when the students were not asked to engage with or critique the mathematics in question, then the presence of mathematical content only served as a superficial marker of credibility. This was most clearly seen at Rho University where students, after being told to look for the presence of a correlation coefficient, judged that articles without a correlation coefficient could not be as credible as those that had one. This sentiment also could be seen as students gathered information for their debates at Phi University as can be seen in Adelle's statement:

[The article] had a bunch of numbers and things. I just couldn't decipher it very easily. But [it is] really good if you want to throw a bunch of facts in somebody's face. (Adelle, First Session, First Group, Session 140602, Lines 130-134)

Adelle sees the presence of mathematics as a useful tool for making an 
argument even in the absence of personal understanding.

On the other hand, if a source contained mathematics that the students did not understand, then they might not use that source. This point may appear obvious, but it serves as an important caveat for any instructor who gives students freedom to locate sources on their own and also exists in tension with the previous observation. One of the teaching assistants described their concerns as they observed this phenomenon in the classroom:

I wish we had done more on stats because ... I don't think even if they did find like a great resource, I don't think they were really able to fully extract the math from it because they didn't understand a lot of the math that it contained. (Rita, Session 130901, Lines 88-92)

Another teacher expressed concern that students' discomfort in the face of more sophisticated mathematical content could lead students away from precisely those information sources that experts would generally deem to be the most credible. This concern reflects a fundamental tension that cannot be easily resolved between the increasing level of expertise that supplies the grounds for treating one source as more credible than another and the decreasing likelihood that a reader will have the expertise to interrogate the mathematics involved in the author's arguments.

\section{Third Tension: Critical Stance as an III-Defined Learning Goal}

This is what numeracy or math literacy is about. First and foremost, being able to see numbers and graphs and tables and it should make sense. If it doesn't make sense then something should immediately click that says "something fishy going on here."- that critical sense, or appraisal. (Ivan, Session 140414, Lines 147-150)

This quote is from the instructor at Delta University describing what he hoped his students would take away from his management of the information-based activity. His primary concern as each group presented their work was that the students (both those in the presenting group and those in the audience) recognize when quantitative claims were not supported by the data that they brought to the issue at stake. The teachers at the other two sites also prioritized their students' development of a critical stance toward quantitative claims, but they operationalized this in distinct ways. For example, Tim at Phi University presented statistics as a tool for convincing other people while noting that others might misuse statistics in service of their own arguments and that students should guard against this. Hence, in his classroom, a critical stance meant adopting a disposition to question the motives of those who furnish quantitative claims. At Rho University, Anne encouraged her students to question the credibility of sources that failed to include mathematical support (such as a correlation coefficient) for quantitative claims. This approach differs from Phi University and 
Rho University due to its focus on a piece of mathematical content as an arbiter of credibility rather than the argument as a whole or on the motivations behind those providing the argument.

As observed in each of these cases, the instructors all wanted their students to be more critical consumers of quantitative claims as they left their classrooms, but there was no evidence of a shared understanding of what it meant to be critical. Should students recognize that statistics could be manipulated to support anyone's agenda? Should they recognize whether an author is providing the mathematical information necessary to support a quantitative claim? Or should they be able to analyze the methodology employed to generate a quantitative claim and recognize when a conclusion is not actually supported by the data? Each question reflects a distinct conception of what it means to be a critical consumer of information. This is not to say that a shared understanding could not be uncovered through further investigation. For example, Frankenstein's definition of critical mathematical literacy - "the ability to ask basic statistical questions in order to deepen one's appreciation of particular issues" and "the ability to present data to change people's perceptions of those issues" $(1990,336)$ - could comfortably encompass all of these teachers' approaches.

\section{Discussion and Conclusion}

I present the tensions introduced by these information problem-solving tasks not to suggest that such instruction is inevitably compromised, but rather to help teachers develop information-based problems with a logic of instruction that leads to clearly articulated learning objectives. In what follows, I will only address the first two tensions described above as I explore the students' development of a critical stance elsewhere (see Erickson 2018).

Can deeper engagement with mathematical content coexist with a project that engages the full information problem-solving process? As students make use of a greater number of sources, the likelihood grows that their analysis of the justification for specific quantitative claims will be superficial if not absent entirely. It may be the case that taking the time to fully engage students in the information problem-solving process will eclipse some mathematical content. It is helpful to recall that similar trade-offs often have to be made as mathematics curriculum evolves over time. It used to be the case that students had to learn to use tables and slide rules to calculate values of logarithms, but such a use of class time is no longer considered productive with the advent of scientific calculators (Tobin 1998). Similarly, if a mathematics teacher wants students to realistically approximate the information problem-solving process, this development may be grounds for a greater focus on locating relevant epistemic communities rather than sticking to mathematical problem solving as it is usually conceived. 
Focusing on the information problem-solving process also highlights the complicated role of mathematical knowledge in these situations. It may be helpful to focus on what a teacher would not want students to do as they seek out and make use of relevant information. It would be problematic if students were to avoid authoritative information sources because they felt that they could not adequately understand the mathematical or statistical argument contained in such a source. It would be equally problematic if students were to employ an information source as support for their own argument simply because it used impenetrable technical language that they felt would intimidate others. We can begin to address such questions by looking at how academics and researchers approach the information problem-solving process. Work in this area suggests that productive activities might include surveying multiple sources of information, seeking out consensus, and assessing the professional standing of those that advocate for the different sides of an issue (Walraven et al. 2008). Students could approximate these activities. At the same time, mathematical content knowledge is sometimes crucial for understanding the content of a claim in the first place, and if we broadly construe mathematical knowledge to include a greater understanding of the way in which knowledge is created and validated in the field, then that knowledge also helps students evaluate the credibility of different information sources.

While we know that content knowledge facilitates information seeking (Bråten et al. 2011), we still need to develop a better understanding of how to teach students to incorporate their content knowledge into the information problem-solving process. This work begins that process in the context of quantitative literacy instruction while highlighting tensions at work in the implementation of information-based problems that may be applicable to teachers in other content fields.

\section{Acknowledgments}

I would like to gratefully acknowledge the help of the necessarily anonymous mathematics professors who graciously agreed to work with me, as well as the support and feedback of Patricio Herbst, Pamela Moss, Elizabeth Moje, and Deborah Ball, and the constructive feedback from two anonymous reviewers of an earlier version of this article.

\section{References}

Brand-Gruwel, Saskia, and Marc Stadtler. 2011. "Solving Information-Based Problems: Evaluating Sources and Information." Learning and Instruction, 21(2): 175-179. https://doi.org/10.1016/j.learninstruc.2010.02.008. 
Bransford, John D., \& Daniel L. Schwartz. 1999. "Chapter 3: Rethinking Transfer: A Simple Proposal with Multiple Implications." Review of Research in Education, 24(1): 61-100. https://doi.org/10.3102/0091732X024001061.

Bråten, Ivar, Helge I. Strømsø, \& Ladislao Salmerón. 2011. “Trust and Mistrust When Students Read Multiple Information Sources about Climate Change." Learning and Instruction, 21(2): 180-192.

Britt, M. Anne, \& Cindy Aglinskas. 2002. "Improving Students' Ability to Identify and Use Source Information." Cognition and Instruction, 20(4): 485-522. https://doi.org/10.1207/S1532690XCI2004_2.

Brousseau, Guy 1997. Theory of Didactical Situations in Mathematics (Didactique des Mathematiques, 1970-1990).(N. Balacheff \& M. Cooper \& R. Sutherland \& V. Warfield, Trans.).

Cullinane, Jenna, \& Philip Uri Treisman. 2010. “Improving Developmental Mathematics Education in Community Colleges: A Prospectus and Early Progress Report on the Statway Initiative. An NCPR Working Paper." National Center for Postsecondary Research.

Diefenderfer, Caren L. 2009. Case Studies for Quantitative Reasoning: A Casebook of Media Articles. Pearson Custom Publishing.

Doyle, Walter, \& Kathy Carter. 1984. "Academic tasks in classrooms." Curriculum Inquiry, 129-149. https://doi.org/10.1080/03626784.1984.11075917.

Erickson, Ander. 2015. "Counting on the Knowledge of Others: Rational Dependence in the Mathematics Classroom.” PhD diss., University of Michigan.

Erickson, Ander. 2016. Rethinking the Numerate Citizen: Quantitative Literacy and Public Issues. Numeracy, 9(2): 4. https://doi.org/10.5038/19364660.9.2.4.

Erickson, Ander. 2018. “Deception/Suspicion/Perception: Defining a Critical Stance in Quantitative Literacy Classrooms." Roundtable Session at the Annual Meeting of the American Educational Research Association, New York, NY.

Frankenstein, M. 1990. Incorporating Race, Gender, and Class Issues into a Critical Mathematical Literacy Curriculum. The Journal of Negro Education, 59(3): 336-347. https://doi.org/10.2307/2295568.

Gal, Iddo. 2002. "Adults' Statistical Literacy: Meanings, Components, Responsibilities." International Statistical Review, 70(1): 1-25. https://doi.org/10.1111/j.1751-5823.2002.tb00336.x.

Graesser, Arthur C., Jennifer Wiley, Susan R. Goldman, Tenaha O’Reilly, Moongee Jeon, \& Bethany McDaniel. 2007. "SEEK Web Tutor: Fostering a Critical Stance While Exploring the Causes of Volcanic 
Eruption.” Metacognition and Learning, 2(2-3): 89-105.

https://doi.org/10.1007/s11409-007-9013-X.

Grafstein, Ann. 2002. "A Discipline-Based Approach to Information

Literacy." The Journal of Academic Librarianship, 28(4): 197-204.

https://doi.org/10.1016/S0099-1333(02)00283-5.

Haas, Peter M. 1992. "Banning Chlorofluorocarbons: Epistemic Community Efforts to Protect Stratospheric Ozone.” International Organization, 46(1): 187-224. https://doi.org/10.1017/S002081830000148X.

Head, Alison. 2013. "Project Information Literacy: What Can Be Learned about the Information-Seeking Behavior of Today's College Students." Association of College and Research Libraries (Hg.): Imagine, Innovate, Inspire. The Proceedings of the ACRL 2013 Conference: Association of College and Research Libraries (ACRL), 472-482. https://doi.org/10.2139/ssrn.2281511.

Hetland, Lois. 2000. "Listening to Music Enhances Spatial-Temporal Reasoning: Evidence for the 'Mozart Effect."' Journal of Aesthetic Education, 34(3/4): 105-148. https://doi.org/10.2307/3333640.

Herbst, Patricio G. 2006. Teaching Geometry with Problems: Negotiating Instructional Situations and Mathematical Tasks. Journal for Research in Mathematics Education, 313-347.

Herbst, Patricio, \& Daniel Chazan. 2012. "On the Instructional Triangle and Sources of Justification for Actions in Mathematics Teaching." ZDM, 44(5): 601-612. https://doi.org/10.1007/s11858-012-0438-6.

Hoffman, Joseph L., Hsin-Kai Wu, Joseph S. Krajcik, \& Elliot Soloway. 2003. "The Nature of Middle School Learners' Science Content Understandings with the Use of Online Resources.” Journal of Research in Science Teaching, 40(3): 323-346. https://doi.org/10.1002/tea.10079.

Kahan, Dan M., Ellen Peters, Erica C. Dawson, \& Paul Slovic. 2017. "Motivated Numeracy and Enlightened Self-government." Behavioural Public Policy, 1(1), 54-86. https://doi.org/10.1017/bpp.2016.2.

Keil, Frank C. 2010. “The Feasibility of Folk Science.” Cognitive Science, 34(5): 826-862. https://doi.org/10.1111/j.1551-6709.2010.01108.x.

Kienhues, Dorothe, Marc Stadtler, \& Rainer Bromme. 2011. "Dealing with Conflicting or Consistent Medical Information on the Web: When Expert Information Breeds Laypersons' Doubts about Experts.” Learning and Instruction, 21(2): 193-204. https://doi.org/10.1016/j.learninstruc.2010.02.004.

Moje, Elizabeth B. 2007. "Developing Socially Just Subject-Matter Instruction: A Review of the Literature on Disciplinary Literacy Teaching." Review of Research in Education, 31(1): 1-44. https://doi.org/10.3102/0091732X07300046001.

National Council on Education and the Disciplines. 2001. Mathematics and 
Democracy: The Case for Quantitative Literacy. L. A. Steen (Ed.). NCED. Norris, Stephen P. 1995. "Learning to Live with Scientific Expertise: Toward a Theory of Intellectual Communalism for Guiding Science Teaching." Science Education, 79(2): 201-217. https://doi.org/10.1002/sce.3730790206.

Paulos, John Allen. 1988. Innumeracy: Mathematical Illiteracy and Its Consequences. Macmillan.

Popper, Karl. 2014. Conjectures and Refutations: The Growth of Scientific Knowledge. Routledge. https://doi.org/10.4324/9780203538074.

Rader, Hannelore B. 2002. "Information Literacy 1973-2002: A Selected Literature Review." Library Trends, 51(2): 242-259.

Schleppegrell, Mary J. 2007. "The Linguistic Challenges of Mathematics Teaching and Learning: A Research Review." Reading \& Writing Quarterly, 23(2): 139-159. https://doi.org/10.1080/10573560601158461.

Shanahan, Timothy, \& Cynthia Shanahan. (2012). "What Is Disciplinary Literacy and Why Does It Matter?" Topics in Language Disorders, 32(1): 7-18. https://doi.org/10.1097/TLD.0b013e318244557a.

Stake, Robert E. 2013. Multiple Case Study Analysis. Guilford Press.

Steen, Lynn A. 2001. Embracing Numeracy. Mathematics and Democracy: The Case for Quantitative Literacy, 107-116.

Steen, Lynn A. 2004. Achieving Quantitative Literacy: An Urgent Challenge for Higher Education (No. 62). MAA.

Tobin, Patrick. 1998. "New Technology and Curriculum Change." Teaching Mathematics and Its Applications: An International Journal of the IMA, 17(3): 97-105. https://doi.org/10.1093/teamat/17.3.97.

Tuominen, Kimmo, Reijo Savolainen, \& Sanna Talja. 2005. "Information Literacy as a Sociotechnical Practice." The Library Quarterly, 75(3): 329345. https://doi.org/10.1086/497311.

Walraven, Amber, Saskia Brand-Gruwel, \& Henny P. Boshuizen. 2008. "Information-Problem Solving: A Review of Problems Students Encounter and Instructional Solutions.” Computers in Human Behavior, 24(3): 623-648. https://doi.org/10.1016/j.chb.2007.01.030.

Watson, Jane M. 2013. Statistical Literacy at School: Growth and Goals. Routledge.

Wiley, Jennifer, Susan R. Goldman, Arthur C. Graesser, Christopher A. Sanchez, Ivan K. Ash, \& Joshua A. Hemmerich. 2009. "Source Evaluation, Comprehension, and Learning in Internet Science Inquiry Tasks." American Educational Research Journal, 46(4): 1060-1106. https://doi.org/10.3102/0002831209333183.

Wilkins, Jesse L. 2010. "Modeling Quantitative Literacy.” Educational and Psychological Measurement, 70(2): 267-290. https://doi.org/10.1177/0013164409344506. 